\title{
COMPARISON OF ERYTHROMYCIN AND OXYTETRACYCLINE FOR THE TREATMENT OF OVINE FOOTROT
}

\author{
S. Píriz ${ }^{1}$, T. PobeL ${ }^{2}$, Ruth Jiménez ${ }^{1}$, E. M. MAteos ${ }^{1}$, P. MARTín-Palomino ${ }^{1}$, \\ Pilar VILA ${ }^{3}$ and S. VADILLO ${ }^{1 *}$ \\ ${ }^{1}$ Unit of Microbiology, Department of Medicine and Animal Health, Veterinary Faculty, \\ University of Extremadura, 10071 Cáceres, Spain; ${ }^{2}$ C/Las Betetas, Soria, Spain; \\ ${ }^{3}$ Sanagro Trade, S. A., Barcelona, Spain
}

(Received April 20, 2000; accepted October 30, 2000)

\begin{abstract}
A microbiological study of 25 cases of ovine footrot was performed. Cultures belonging to Dichelobacter nodosus were isolated in $48 \%$ of the sampled animals. The sensitivity of the 99 strict anaerobic bacterial isolates to 5 antibiotics (penicillin G, amoxycillin, spiramycin, erythromycin and oxytetracycline) was studied. The percentage of resistant cultures was in all cases higher than $30 \%$. The efficacy of erythromycin and oxytetracycline in the treatment of ovine footrot was studied. To conduct this test, an intramuscular injection was applied, of one antimicrobial or the other, at the beginning of the treatment. The tolerance of animals to the antimicrobials, the success rate of treatment and the severity of lameness were evaluated. The percentage of animals cured within 15 days was around $75 \%$. In contrast, only $44 \%$ improvement was achieved in the lameness. No differences were found between the two antimicrobials in the above indices.
\end{abstract}

Key words: Erythromycin, oxytetracycline, treatment, ovine, footrot

Ovine footrot is an illness or, more appropriately, an infectious syndrome of sheep that is characterised by exudative swelling followed by ischaemia and further tissue necrosis of the hoof that can result in the detachment of the corneous case. The main microbial agent causing this infectious illness is the strict anaerobic bacterium Dichelobacter nodosus (ex Bacteroides), a microorganism frequently associated with Fusobacterium necrophorum and Arcanobacterium pyogenes. There are a series of predisposing factors that favour the pathogenic action of these microorganisms. These include humidity, temperature, state of the ground, weight of the animals, etc. (Hurtado et al., 1998).

This syndrome is responsible for major economic losses to the sheep production sector in Spain (an about 10\% decrease in mutton and wool production and a $20 \%$ decrease in milk production). The cited losses are due to the intense pain that ovine footrot causes in the affected extremity, the resulting sign of intense lameness, and the animals' great difficulty of movement and feeding them-

*Corresponding author; E-mail: svadillo@unex.es; Fax: +34 (927) 257110 
selves. This illness is extremely contagious and can affect up to $75 \%$ of the animals in a flock (Brugère-Picoux, 1994).

Different molecules with antimicrobial activity, among others the penicillin-streptomycin combination, erythromycin and oxytetracycline have been used for the treatment of this infection. A few years ago, Webb Ware (1994) studied the efficacy of the erythromycin, at different dosages, in comparison with other molecules widely used in the treatment of this illness, such as the penicillin and streptomycin combination. The cited researchers demonstrated the superiority of an only intramuscular injection of erythromycin, at a dosage of $10 \mathrm{mg} / \mathrm{kg}$, over any other antimicrobial treatment.

The primary objective of our study was to compare the efficacy of the pharmaceuticals Pantomicina ${ }^{\circledR} 200$ (Sanofi Santé Nutrition Animale, injectable solution of erythromycin at a concentration of $200 \mathrm{mg} / \mathrm{ml}$ ), used in an only intramuscular injection at a dosage of $10 \mathrm{mg} / \mathrm{kg}$, and of the Terramicina ${ }^{\circledR}$ L.A. preparation (Pfizer, Inc., injectable dehydrate solution of oxytetracycline at a concentration of $200 \mathrm{mg} / \mathrm{ml}$ ), used in an only intramuscular injection at a dosage of $20 \mathrm{mg} / \mathrm{kg}$. In addition, the tolerance of these pharmaceuticals under these conditions of use was evaluated. This study was carried out in accordance with the regulations of Good Clinical Practice, according to Directive 92/18/EEC of the European Economic Community and Guideline III/3767/92 Final.

\section{Materials and methods}

The study was conducted during the autumn of 1998, with a total of 103 sheep distributed among 3 different pastures of the province of Cáceres (Spain). Of these animals, 33 belonged to a pasture situated in Rosalejo, 28 grazed on a farm in Portezuelo and 42 formed part of a flock in Valdefuentes. A multicentre, blind, random and comparative test of the ground was conducted.

The pastures were selected according to their record and the clinical suspicion of footrot. The subsequent demonstration, through bacteriological analysis, of the aetiological agent, Dichelobacter nodosus allowed the inclusion of each pasture in the study.

The first day (D1) specimens were collected for the bacteriologic analysis which demonstrated the presence of the aetiological agent. The collection of specimens (pathologic material of the affected hooves, pus, necrotic tissue or simply scrapings from the reddened skin) was carried out using a Trans-Cul hyssop (Buoty Diagnostic) or Eurotubo Transport (Industrias Aulaber, S. A.) which contain the incorporated media of Stewart (Belfield, 1985) and Amies (Amies and Path, 1967), respectively. The specimens were transported rapidly to the laboratory under refrigerated conditions, using isothermic containers that main- 
tain the interior temperature between 4 and $6{ }^{\circ} \mathrm{C}$. In order to carry out the cited analysis, only 25 of the 103 selected animals were sampled.

The bacteriological analysis was conducted in the Microbiology and Immunology Laboratory of the Veterinary College of Cáceres (University of Extremadura, Spain). All the footrot specimens were inoculated onto three different cultivation media: Agar Brucella supplemented with 5\% ram blood (BR), Agar Brucella enriched with G-N anaerobe supplement and enriched with 5\% ram blood (GN) and Fusobacterium agar egg yolk (AYA). For the identification of the strict anaerobic bacteria, the procedures described by Holdeman et al. (1977), Sutter et al. (1985), Summanen et al. (1993) and Volumes I and II of Bergey's Manual (Krieg and Holt, 1984; Sneath et al., 1986) were used, which are based fundamentally on the use of gas-liquid chromatography to detect the volatile and non-volatile fatty acids that appear as final products of glucose metabolism, as well as on the study of the fermentation of carbohydrates and other biochemical tests. Finally, an antibiogram was conducted (by diffusion method in agar) on all of the strict anaerobic bacteria isolated and identified in this study. The following antimicrobials were used: penicillin G, amoxycillin, oxytetracycline, erythromycin and spiramycin. This susceptibility testing was conducted according to the criteria established by the National Committee for Clinical Laboratory Standards (M11-A2, 1990).

On each selected pasture, two groups of animals were taken, which were treated with Pantomicina ${ }^{\circledR} 200$ or with Terramicina ${ }^{\circledR}$ L.A. Both treated groups were observed in parallel. In order for the test to be carried out in a completely blind manner, it was the monitor who conducted the treatment and the researcher who was in charge of the clinical observations without knowing the treatment given. The monitor disposed of, for each pasture, a random attribution list for the preestablished treatment and stratified based on the severity of the lesions. The products were administered using disposable syringes and needles. During the 15 days that the test lasted, it was totally prohibited to conduct any type of supportive treatment, either general or local (including the use of foot baths or zinc supplementation).

Male or female animals of any age and type of production were included in the study, except lactating females whose milk was destined for human consumption. The animals had to show characteristic lesions of footrot in one or several extremities, with or without lameness.

The lesions were graded according to the following classification:

0 : $\quad$ Normal foot,

+ Slight interdigital dermatitis with hyperkeratosis,

++ Interdigital dermatitis with serous exudate and erosion clearly associated with footrot,

+++ : Extension of the lesion to the heel and the sole of the foot,

++++ : Extension of the lesion to the entire hoof. 
The animals were included in the study starting from stage + . All of the animals were identified with a ring in their ear which indicated their inclusion number in the experiment. The age of the animals included in this study was 5.5 \pm 2.1 years old and their average body weight was $40.8 \pm 8.1 \mathrm{~kg}$.

The clinical observations (lesion and lameness) for the inclusion, the attribution of the treatment and the initial observation were carried out by the researcher on the first day (D1). These same observations were conducted again on the 8th day (D8) and the 15th day (D15). Furthermore, on the second day the tolerance of local anaesthesia was evaluated. The lesions were observed individually for the 4 extremities of each animal and were assigned scores according to the classification described above. Lameness was observed individually and scores were assigned according to the following classification: 0 : absence, 1 : slight reduction of the support time, 2: obvious reduction of the support time and obvious 'falling' movement, even total suppression of the support. In the administration records, prepared for each animal, the behaviour of each individual during the injection was indicated. The evaluation was conducted according to the following parameters: 0 : absence of reaction, 1: movement of defence.

\section{Results}

The animals that belonged to the three pastures studied are comparable in all of the observed criteria (severity of lesions, number of affected animals and type of lameness).

On all three pastures, the bacteriological results confirmed the presence of ovine footrot. The aetiological agent of the illness, Dichelobacter nodosus, was isolated on all of the pastures. In addition to this microorganism, large numbers of anaerobic bacteria were obtained. The microorganisms most frequently isolated, after Dichelobacter nodosus, were the following: Veillonella parvula, Fusobacterium necrophorum, Prevotella intermedia, Prevotella oralis, Prevotella spp., Fusobacterium spp., Megasphaera elsdenii and Porphyromonas levii. The complete list of the isolated bacteria, as well as their isolation frequencies, are shown in Table 1.

The sensitivity of the 99 anaerobic bacteria cultures to the five antimicrobials used in this study is shown in Table 2 . As can be inferred by observing the table, the percentage of sensitive anaerobic bacteria was very similar (around $60 \%$ ) for all of the antimicrobials. Despite the similar behaviour of all antimicrobials, it must be emphasised that the lowest percentage of antibiotic resistance was obtained for erythromycin (31\% of the studied cultures).

As regards the tolerance shown in all 103 animals included in this study, none of them showed a tolerance reaction (tumefaction) to erythromycin and oxytetracycline at the moment of inoculation. Moreover, only 9 and 4 animals showed a slight reaction during the injection of Terramicina ${ }^{\circledR}$ (oxytetracycline) and Pantomicina ${ }^{\circledR} 200$ (erythromycin), respectively. 
Table 1

Species of strict anaerobic bacteria isolated from 25 cases of ovine footrot

\begin{tabular}{lcc}
\hline \multicolumn{1}{c}{ Bacterium species } & No. of cultures & Percentage \\
\hline Dichelobacter nodosus & 12 & 48 \\
Veillonella parvula & 8 & 32 \\
Fusobacterium necrophorum & 6 & 24 \\
Prevotella intermedia & 6 & 24 \\
Prevotella oralis & 6 & 24 \\
Prevotella spp. & 6 & 24 \\
Fusobacterium spp. & 5 & 20 \\
Megasphaera elsdenii & 4 & 16 \\
Porphyromonas levii & 4 & 16 \\
Fusobacterium mortiferum & 3 & 12 \\
Fusobacterium perfoetens & 3 & 12 \\
Fusobacterium nucleatum & 3 & 12 \\
Bacteroides spp. & 3 & 12 \\
Clostridium spp. & 3 & 12 \\
Bacteroides pyogenes & 2 & 8 \\
Clostridium bifermentans & 2 & 8 \\
Clostridium subterminale & 2 & 8 \\
Fusobacterium necrogenes & 2 & 8 \\
Fusobacterium rusii & 2 & 8 \\
Peptostreptococcus prevoti & 2 & 8 \\
Porphyromonas endodontalis & 2 & 8 \\
Prevotella melaninogenica & 2 & 8 \\
Prevotella ruminicola & 2 & 8 \\
Propionibacterium spp. & 2 & 4 \\
Acidaminococcus fermentans & 1 & 4 \\
Bacteroides capillosus & 1 & 4 \\
Bacteroides ureolyticus & 1 & 4 \\
Gemella morbillorum & 1 & 4 \\
Peptostreptococcus asaccharolyticus & 1 & \\
Peptostreptococcus indolicus & 1 & \\
Peptostreptococuss magnus & & \\
\hline & & \\
\hline
\end{tabular}

Table 2

Percentage of cultures resistant to the 5 antimicrobial agents used in the study

\begin{tabular}{lccc}
\hline \multicolumn{1}{c}{ Antimicrobial agent } & $\begin{array}{c}\text { Susceptible } \\
\%\end{array}$ & $\begin{array}{c}\text { Intermediate } \\
\%\end{array}$ & $\begin{array}{c}\text { Resistant } \\
\%\end{array}$ \\
\hline Penicillin G & 63 & 1 & 36 \\
Amoxycillin & 58 & 7 & 35 \\
Spiramycin & 62 & 2 & 36 \\
Erythromycin & 60 & 9 & 31 \\
Oxytetracycline & 59 & 4 & 37 \\
\hline
\end{tabular}


The success rate of treatment, expressed in per cent, is shown in Fig. 1. These observations were made on the 8th and the 15th day after the application of the treatment. On the 8th day, 27 of the animals treated with Pantomicina ${ }^{\circledR} 200$ $(54 \%)$ and 25 of the animals injected with Terramicina ${ }^{\circledR}(50 \%)$ were cured. When the animals were inspected 15 days later, the number of cured animals, among those treated with Pantomicina ${ }^{\circledR}$ 200, was found to have reached 38 $(76 \%)$. Finally, 37 of the animals injected with Terramicina ${ }^{\circledR}(74 \%)$ were considered to have overcome this infectious illness. In neither of the two cases could we find a statistical difference between the two antimicrobials in the success rate of treatment $(\mathrm{x}=0.05$ with 1 degree of freedom, $\mathrm{p}=0.82)$.

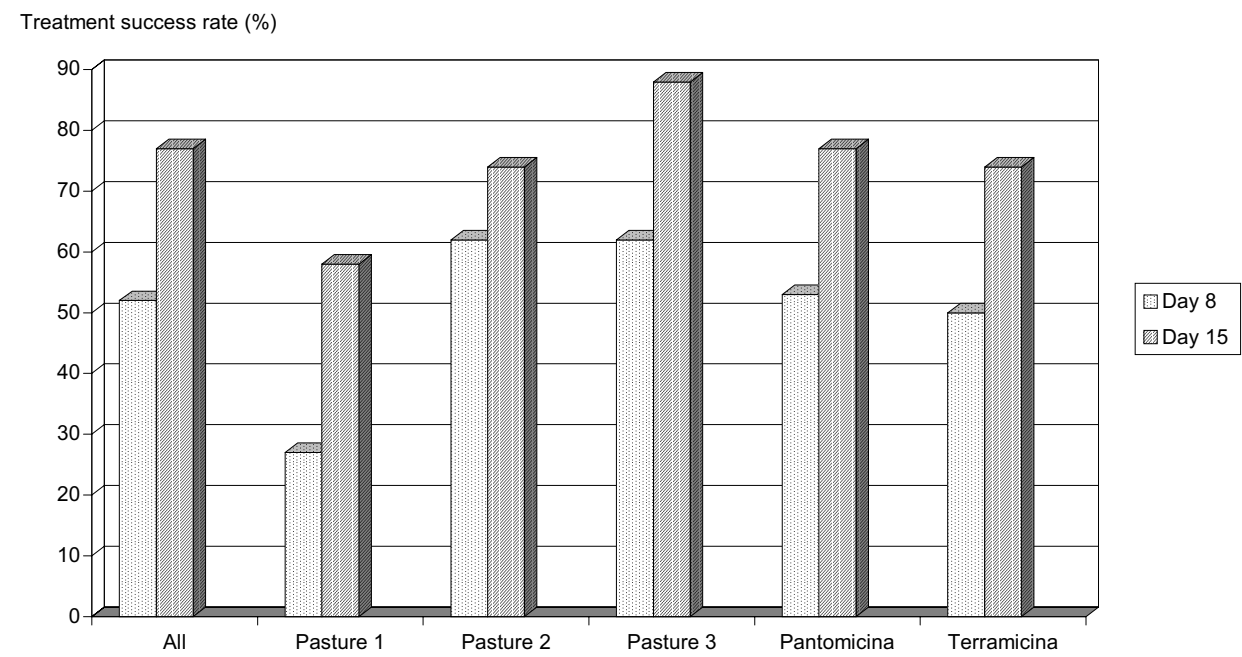

Fig. 1. Success rate of treatment in the animals included in the study. No statistically significant differences were found in the success rate of treatment between Pantomicina ${ }^{\mathbb{B}} 200$ and Terramicina ${ }^{\circledR}$ L.A.

The results obtained when analysing the evolution of lameness are shown in Fig. 2. This figure shows that there was no difference between the two medications in the percentage of animals showing an improvement in their condition, an increase in the intensity of lameness or unchanged condition as compared to the beginning of the treatment. Consequently, it can be established that no significant differences exist between the two products in their efficacy for the reduction of lameness. Finally, it must be mentioned that the percentage of cured animals (around 75\%) is clearly superior to the percentage of animals that show an improvement in their lameness condition (around 44\%). 


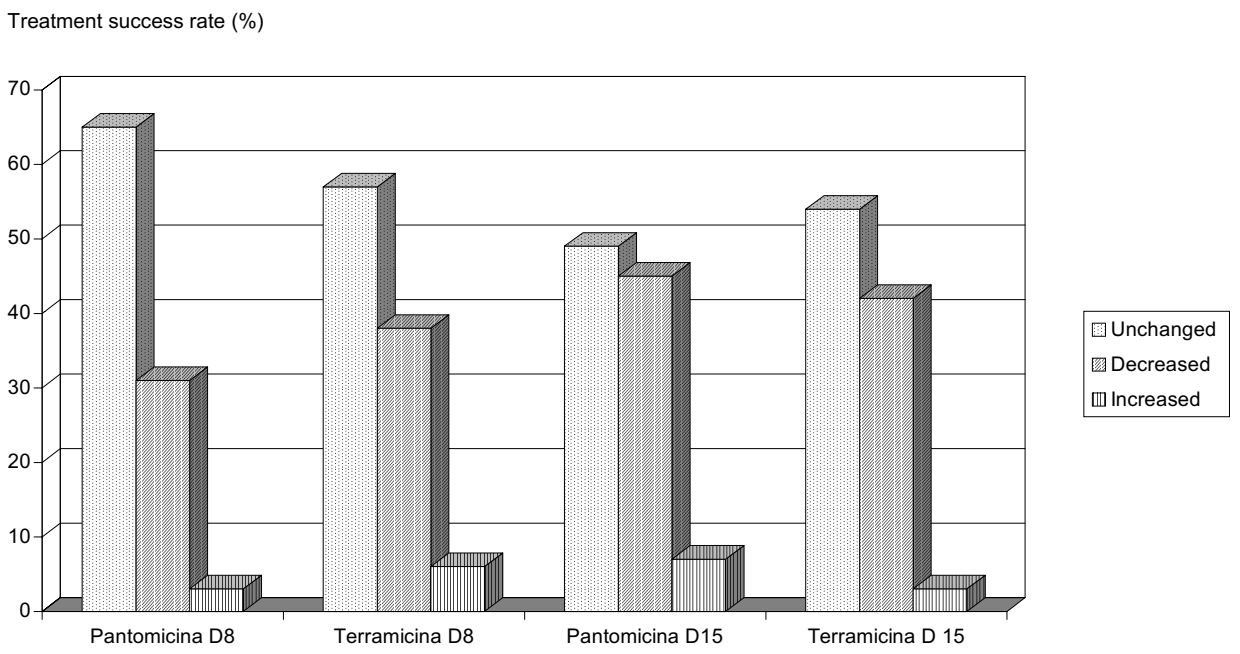

Fig. 2. Lameness status of the animals on post-treatment days 8 and 15 , as compared to their pretreatment condition

\section{Discussion}

Dichelobacter nodosus was isolated in $48 \%$ of the studied cases, while Fusobacterium necrophorum was found in $24 \%$ of the processed specimens. The percentage of isolation of Dichelobacter nodosus is similar to that found by Píriz et al. (1990) when carrying out a microbiological study of ovine footrot in the province of Cáceres. However, the above-cited authors isolated Fusobacterium necrophorum only from $8.8 \%$ of the samples analysed. Hurtado et al. (1998) isolated 460 strict anaerobic bacteria from 216 samples obtained from cases of ovine footrot in different areas of Spain. The predominant species was Dichelobacter nodosus, which was isolated in 168 cases (77.8\%). A high percentage of the cultures isolated by these researchers showed elastolytic activity, considering that 118 cultures degraded elastin. Finally, in the above-cited work, microorganisms belonging to the Prevotella genus were isolated in 96 cases (44\%). In this study, a remarkable number of cultures belonging to the Prevotella genus were also isolated: Prevotella intermedia (6 cultures), Prevotella oralis (6 cultures), Prevotella spp. (6 cultures), Prevotella melaninogenica (2 cultures) and Prevotella ruminicola ( 2 cultures).

As regards the sensitivity of cultures to the five antimicrobials used (erythromycin, oxytetracycline, spiramycin, penicillin $G$ and amoxycillin), it can be established that the percentage of resistant cultures ranged between $31 \%$ resistance to erythromycin (the most effective agent) and 37\% resistance to oxytetracycline. 
These results are different from those obtained by Autef et al. (personal communication) who observed 13\% resistance to erythromycin for 47 strict anaerobic bacterial cultures isolated from 197 sheep in an efficacy study of erythromycin and oxytetracycline in the treatment of footrot. Furthermore, none of the cultures studied by them was resistant to oxytetracycline. However, the highest antibiotic resistance found by these authors to erythromycin does not correspond to the clinical results obtained. This fact is very well known in human medicine and it is due to the fact that the conditions in the cultivation medium are very different from those that exist in live or necrotic tissues.

The use of injectable erythromycin (Pantomicina ${ }^{\circledR} 200$ ) and oxytetracycline (Terramicina ${ }^{\circledR}$ L.A.) in the normal rearing of extensive flocks of sheep, according to a simple and original outline, has permitted the collection of comparable results for both antimicrobials. Indeed, the treatment of animals affected with footrot, using as criteria the degree of evolution of injuries, exceeded $50 \%$ on the 8th day and was around $75 \%$ on the 15 th day. Autef et al. (personal communication) obtained cure rates slightly superior to ours. Namely, the above French researchers observed $86.3 \%$ and $84.5 \%$ cure rates in sheep treated with erythromycin and oxytetracycline, respectively. Furthermore, in the cited study, it was observed that animals with the most severe lesions $(+++$ or ++++$)$ showed a treatment success rate significantly $(\mathrm{p}<0.001)$ superior to that seen in the less severely affected animals $(+$ or ++$)$.

The literature contains few studies that could serve as a comparison for the present results. Of them, the study conducted by Morck et al. (1998) can be highlighted, in which the efficacy of ceftiofur sodium and oxytetracycline for the treatment of acute interdigital phlegmon (footrot) was compared in feedlot cattle. The results of this study show that erythromycin, administered in a dose of $10 \mathrm{mg} / \mathrm{kg}$, i.m., every $24 \mathrm{~h}$ for 3 days was as effective as oxytetracycline $(6.6 \mathrm{mg} / \mathrm{kg}$, i.m., every $24 \mathrm{~h}$ for 3 days) in the treatment of this infectious disease.

As regards the improvement of lameness, this seems to be slower and less expressed. This is believed to be due to the fact that lameness is not only the direct result of the infectious process of footrot, but that other factors also intervene (postural defects, traumas, etc.). Consequently, an improvement in lameness was observed only in $45 \%$ of the cases, but it can be inferred that the actual improvement rate of footrot, strictly due to the alleviation of suffering, is higher.

\section{References}

Amies, C. R. and Path, M. R. C. P. (1967): A modified formula for the preparation of Stuart's transport medium. Can. J. Publ. Health. 58, 296-300.

Autef, P., Couquet, C., Tessier, Ph. and Mage, C. (2000): Efficacy of injectable erythromycin in the treatment of ovine footrot (in French). Personal communication. 
Belfield, A. J. M. (1985): Evaluation of laboratory tests for distinguishing between field strains of Bacteroides nodosus. In: Stewart, D. J., Peterson, J. E., McKern, N. M. and Emery, D. L. (eds) Foot Rot in Ruminants. Proceedings of a Workshop, CSIRO Division of Animal Health, Australian Wool Corporation, Melbourne, 1985, pp. 93-98.

Brugère-Picoux, J. (1994): Les affections de l'appareil locomoteur. G. T. Vet. 94, 167.

Committee for Veterinary Medicinal Products Working Party on Efficacy (1992): Note for guidance. Good clinical practice for the conduct of clinical trials for veterinary medicine. European Commission. III/3767/92 Final.

Commission of the European Communities (1992): Directive 92/18/EEC de la Commission du 20 mars 1992, modifiant l'annexe de la directive 81/852/EEC du Conseil relative au rapprochement des législations des États membres concernant les normes et protocoles analytiques, toxico-pharmacologiques et cliniques en matière d'essais de médicaments vétérinaires. Off. J. Eur. Commun. L/97/1.

Holdeman, L. V., Cato, E. P. and Moore, W. E. C. (eds) (1977): Anaerobe Laboratory Manual, 4th edition. Virginia Polytechnic Institute and State University, Blacksburg, Virginia.

Hurtado, M. A., Píriz, S., Valle, J., Jiménez, R. and Vadillo, S. (1998): Aetiology of ovine footrot in Spain. Vet. Rec. 142, 60-63.

Krieg, N. R. and Holt, J. G. (eds) (1984): Bergey's Manual of Systematic Bacteriology. Vol. 1. 9th edition. Williams and Wilkins, Baltimore.

Morck, D. W., Olson, M. E., Louie, T. J., Koppe, A. and Quinn, B. (1998): Comparison of ceftiofur sodium and oxytetracycline for treatment of acute interdigital phlegmon (foot rot) in feedlot cattle. J. Am. Vet. Med. Assoc. 212, 254-257.

National Committee for Clinical Laboratory Standards (1990): Methods for antimicrobial susceptibility testing of anaerobic bacteria. Approved standard M11-A2. National Committee for Clinical Laboratory Standards, Villanova, PA.

Píriz, S., Cuenca, R., Valle, J. and Vadillo, S. (1990): The isolation and identification of anaerobic bacteria from ovine footrot in Spain. Res. Vet. Sci. 49, 245-247.

Sneath, P. H. A., Mair, N. S., Sharpe, M. E. and Holt, J. G. (1986): Bergey's Manual of Systematic Bacteriology. Vol. 2. 9th edition. Williams and Wilkins, Baltimore.

Summanen, P., Baron, E. J., Citron, D. M., Strong, C., Wexler, H. M. and Finegold, S. M. (1993): Wadsworth Anaerobic Bacteriology Manual. 5th edition. Star Publishing Company, Belmont, California.

Sutter, V. L., Citron, D. M. and Edelstein, M. A. C. (1985): Wadsworth Anaerobic Bacteriology Manual. 4th edition. Star Publishing Company, Los Angeles.

Webb Ware, J. K. (1994): Efficacy of erythromycin compared with penicillin and streptomycin for the treatment of virulent footrot in sheep. Aust. Vet. J. 3, 87-88. 